\title{
An Interview with Professor David W. Lewis
}

\author{
GARY MCGUIRE
}

\section{INTRODUCTION}

On 20 July 2009 I conducted an informal interview with David, who officially retired in 2009.

\section{BACKGROUND AND EDUCATION}

\section{GMG: As a child were you interested in mathematics?}

DL: To the extent that a child can be, yes I was. I was also interested in things like football and sports and so on, and I wasn't interested in mathematics in an academic sense until late in secondary school. In primary school I liked mathematics, and I was always good at mathematics. In secondary school I was even more interested in physics, and astronomy. If I had any ideas of studying a subject it was physics or astronomy. It was only in the last year of my secondary school that I realized I was better at mathematics than anything else. That's when I decided to study it at university.

\section{GMG: What part of the world was this?}

DL: I was born and grew up in Douglas, Isle of Man. I went to school there, both primary and secondary. My secondary school was called Douglas High School.

\section{GMG: Did you have any good teachers in school?}

DL: Yes, one teacher I had for the last two years, named Henry Corlett, he was very very good. He had a degree from Cambridge University, and he was excellent. Before that I had a good teacher named Ted Kelly, whose nickname was The Mekon. You probably don't remember a comic called The Eagle, which had a character called Dan Dare. There was another character called the Mekon, 
the enemy of Dan Dare, who had a big bald head. Ted Kelly had a big bald head, so we called him the Mekon. But he was a very good teacher. Henry Corlett was a tremendous teacher, I met him a few years ago in the Isle of Man. He is now retired of course, but still going strong.

\section{GMG: How did you decide what to study at university?}

DL: In sixth form, we were divided into two streams, arts and science. In my day, this was the 1960s, science was very much the "in" subject. Maybe science is not so popular nowadays, but certainly in those days science was a subject people would go for. Whereas, for things like medicine, well I knew almost nobody who did medicine. Medicine was only for doctors' sons and daughters. Also very few people did commerce and law.

The teachers seemed to advise us that way. I had a friend who wanted to do engineering, but I remember a teacher advising him not to. But he wanted to do it, so he ignored them and went to Liverpool to study engineering, and he was very happy. It seemed that teachers looked down on the professional subjects at that time.

GMG: You went to university in Liverpool. Did many students from the Isle of Man go there?

DL: They would have done. In those days certainly Liverpool was the closest point, and was the easiest point to get to. There was a boat twice a day between Douglas and Liverpool, which had been running for at least the previous hundred years. Many people from the Isle of Man went to Liverpool to work and live. At my time, most people going to university would go to Liverpool university. That probably changed over the next twenty or thirty years, as travel became easier. Most people went to a university in the UK. I can recall a couple of people going to TCD, but I can't recall anyone going to UCD.

GMG: During your undergraduate days, did you study mostly mathematics?

DL: Yes, but when I started I was interested in studying physics, and also applied maths. I did physics for two years. I was quite interested in applied maths, however I found that I didn't like it 
very much, but I liked the pure maths very much. It had a kind of cleanness and purity to it that the applied maths didn't seem to possess. I found that applied maths made assumptions that were hardly justifiable, which didn't appeal to me.

\section{GMG: Did you have any good lecturers at Liverpool?}

DL: Yes, one man called Michael (M.C.R.) Butler, was very good, he was an Australian algebraist. He was married to an applied mathematician, Sheila Brenner. I was very impressed by Butler. Another good person was Geoff Horrocks, he never used any notes and gave these superb lectures, never making a mistake. He got the professorship in Newcastle afterwards.

\section{Early Mathematical Career}

\section{GMG: You began your PhD in Liverpool, I believe.}

DL: Yes, after I finished my undergraduate degree at Liverpool I began a PhD under Terry (C.T.C.) Wall. The topic was surgery obstruction groups, however it was quite algebraic and had a lot to do with Hermitian forms and quadratic forms. I was trying to do some topological aspects to start with, but I found that I was more suited to the algebraic aspects, so I became an algebraist instead of a topologist. Most of Wall's students found him hard to understand, including me. He wasn't the world's greatest expositor.

In those days at Liverpool there was a tremendous emphasis on topology. Somebody seemed to believe that topology was the "in" subject of the 1960s. They appointed a lot of topologists to the staff, both algebraic and differential. We were all encouraged to do topology.

\section{GMG: How did you come to take a position at UCD?}

DL: My PhD funding ended in 1968 and I needed a job, so I looked in the newspapers and I saw an ad for a job in UCD. I applied, got invited for an interview, and then I was offered a position, which I accepted. I was interviewed by Dick Timoney, Phil Gormley, Maurice Kennedy, Tony Christofides, and Tommy Nevin who was dean of science. I remember that I got the impression that Dick Timoney was head, but in fact it was Phil Gormley who was head. 
I had visited Ireland before, coming from the Isle of Man you are more or less half-way between Ireland and England. When I was in Liverpool some people used to accuse me of being Irish, and when I came to Dublin people used to accuse me of being English!

Two other people were appointed in mathematics in UCD that same year, Tom Laffey and David Tipple. This was quite an increase in numbers in mathematics, because before that there was only Phil Gormley, Dick Timoney, Maurice Kennedy, Stephen O'Brien, Fergus Gaines, and Paddy McNeice who used to teach the engineers.

I was appointed as an assistant lecturer. There was even a grade below that, which was called assistant. We had no contract, and we were appointed from year to year. There was no guarantee you would be appointed the following year. You just had to trust that you would. Dick Timoney told us not to worry, that we would be appointed. You had to become statutory lecturer, which was an NUI position, before you were safe. To be dismissed as a statutory lecturer required a court order signed by three high court judges!

\section{GMG: Phil Gormley was head at that time.}

DL: Yes, it seemed like Dick Timoney was head because he did much of the work, but Gormley was head. Phil Gormley was a man of few words, but he chose his words very carefully. His instructions for marking exams were very interesting, he gave a simple four word instruction: "No Marks For Rubbish." Nowadays we have careful marking schemes, so his instructions would not be considered best practice these days.

Gormley was interested in classical analysis, and he used to say "let's do some real mathematics." I don't know why he appointed people in algebra, because he wouldn't have considered algebra as real mathematics. He came from the Derry area, and went to St. Columb's College there. His two brothers Tom Gormley and Paddy Gormley were nationalist members of parliament at Stormont.

Dick Timoney was very efficient at running the department. He had been given a personal chair in the 1960s, so he was also professor of mathematics.

The first year I was at UCD Phil Gormley asked me to attend a committee on the Leaving Certificate mathematics syllabus. I didn't know anything about the Leaving Cert at the time, not having grown 
up in Ireland. It turned out that they had already developed a syllabus, and Gormley was fed up with them because he didn't agree with what they were doing, so he asked me to go instead of him. At least we got a free dinner in Wynn's hotel. A lot of transformation geometry was on the syllabus then, which has mostly been removed now.

\section{GMG: Maurice Kennedy was also a professor?}

DL: He was an associate professor, he was appointed in the 1960s to that grade, as was Stephen O'Brien. The famous story in UCD is that the next round of promotions to associate professor did not happen until the 1980s! So anyone who missed out on promotion to associate professor in the 1960s had to wait about 18 years for another chance.

\section{GMG: Where was your first office?}

DL: My first office was in Earlsfort Terrace. I had to travel to Belfield to lecture to first science, on Saturday mornings. In about 1970 the arts building (now called the Newman Building) was opened and we were given offices there, on the second floor of block F. We remained there until about 2002 when we were moved to the Science buildings.

\section{GMG: So you ended up at the third point of a triangle.}

DL: That's right, I have lived in three places, Douglas, Liverpool, and Dublin, which form a nice triangle.

\section{Later Mathematical Career}

\section{GMG: How was research going in the 1970s?}

DL: I had not yet finished my PhD when I got the UCD job, so I was working to finish that. I published a couple of papers before I actually submitted my thesis. Tom Laffey and Fergus Gaines started an algebra seminar in UCD, which was interesting and helpful. Tom started to work with Fergus on matrix theory questions. The older people in the department didn't do research, at that time. 


\section{GMG: What were your early papers on?}

DL: I wrote about Hermitian forms, defining a signature on some manifolds. It was algebra with applications to manifolds, and topology. I wrote a couple of papers on that kind of stuff. I became much more algebraic after that, working on the algebraic theory of quadratic forms, central simple algebras and other kinds of algebras.

\section{GMG: Who were the big influences on your career?}

DL: One big influence on me was David K. Harrison, who visited Dublin in the early 1970s. He gave a series of lectures on quadratic forms and the work of Pfister and so on. I didn't know this work before then, but I got interested in that area after his lectures. It was close to my previous work, but more algebraic.

Then Lam's book came out after that, and that was also a big influence. Lam refers to lectures at the University of Kentucky by Harrison, so Harrison seems to have influenced the area although he didn't publish much in the area. He ended up in Eugene, Oregon, I think.

Locally, Tom Laffey was a good influence on me. He was always available to talk to about algebra, or indeed, about any area of mathematics. Farther afield, other people I started to collaborate with in the 1980s were an influence on me. Working with Jean-Pierre Tignol in Louvain-la-Neuve was very good for me. He is a great guy to work with. Also Jan van Geel in Ghent has been a great collaborator for me. This connection led to an Erasmus programme.

\section{GMG: Could you tell me more about this Erasmus ex- change.}

DL: We set up an Erasmus programme between Ghent and UCD. Mainly it was myself and van Geel, but also Tom Laffey and Fergus Gaines were involved. Students from either university could visit the other university, for a year, and take some courses. Mostly it seemed that Belgian students came to UCD, rather than the other way around. I'm not sure why, but perhaps it was the language. The exchange still goes on, in fact. The first student to visit here was in 1989 , and there was one here in 2009. Two of the students became $\mathrm{PhD}$ students of mine. So Belgium has been a big influence on me. 


\section{GMG: You were also involved in a European network.}

DL: I got involved with people in several European countries, France, Belgium, Germany, and so on. We applied for and got money to set up an EU research training network, it would fund postdocs and $\mathrm{PhD}$ students to visit another university. Staff could also visit other places. It was very good and beneficial. The idea of the EU was that the leaders of tomorrow, whether they be scientific or industrial or political, if they got together as students and got to know each other they would be more friendly in the future and it would make the EU stronger. They put money into it, in the 1990s, which they did not do in the 1970 s or $1980 \mathrm{~s}$.

\section{Mathematics In General}

GMG: How do you think mathematics has changed over your career?

DL: In general, I think people go more for the applications of mathematics now than they did. In my day in the 1960s people were more into pure maths. Obviously research funding is much more important now than it was then, and people go more for applied or applicable mathematics. There are more mathematicians around, more mathematics is being done, of all kinds. But there is a swing towards applied mathematics.

\section{GMG: Is that good or bad?}

DL: There is certainly room for both. You need to have a reservoir of pure mathematics in order to have some mathematics that can be applied at a later stage. If you don't have that reservoir, you've got nothing to apply. So they both play an important role.

Computer science has also had an effect on what people study. I remember back in the 1970 s when a man named McConalogue was head of computer science here. Computer science was not given good facilities in those days, and the entire staff were located in portacabins in a car park. Now they have their own building. How things have changed! 
GMG: How do you do research, do you work whenever you get an idea?

DL: I don't work in the middle of the night, if I get an idea then. I would wait until the morning to work on it. Sometimes I have woken up in the morning with a good idea. Ideas can come at strange times. I remember one idea came to me when I was laying a carpet.

\section{GMG: Did you finish laying the carpet?}

DL: Oh yes, I finished laying the carpet before working on that idea. My wife would not have accepted the excuse that I had just had a brilliant idea so I was not going to lay the carpet anymore!

\section{GMG: How should Ireland develop in mathematics?}

DL: I think Ireland should certainly continue to do research. It's a shame that not much money is going into basic research at present. Given the current financial status, it doesn't seem that the mathematical models were much use, does it. I think human behaviour is far too complicated to predict. Anyway, Ireland is a small country so we can't be expert in everything, there aren't enough mathematicians to do that. We have to specialize a bit.

Nowadays there is a lot more collaboration with people abroad. The old slogan for the navy used to be "join the navy and see the world" but I think we could say "do mathematics and see the world." I have been able to travel to many countries and continents. Mathematics is sort of a universal language, so you can talk to people all over the world. You can meet someone you've never heard of, in a place you've never heard of, and you can find that they have read some paper you wrote. It's kind of satisfying, in a way.

\section{GMG: How has UCD changed over your career?}

DL: When I first started at UCD I had the naive belief that the administration was there just to ensure that the academic work, teaching and research, went as smoothly as possible. I realized that some administrators believe that the administration exists for its own sake, and not for the academic work. There was a dispute in the library in the early 1970s and there was a strike with pickets, and the university was closed for a week. The registrar at the time was Tom Murphy, who went on to be president. I still remember him 
saying on the television that "it's only the academic work that has been affected by this strike. Normal administration is going on as usual." That made me realize that the administration goes on and has nothing to do with the academic work.

There were many fewer administrators in the early days, than there are now. I'm not sure that things work any better nowadays. Of course there has to be a certain amount of administration, but I used to think that a university was about teaching and research.

GMG: Have you any thoughts on the Mathematical Olympiad?

DL: I think it's good and it helps teach students to solve problems. The problems are very hard, and usually require some cunning and clever trick, and I'm not sure this is a good thing. It is not necessarily representative of mathematics. You can ask if it is the right way to learn mathematics. Students who come to UCD having attended olympiad training think that everything can be done by some clever trick, but sometimes a student has to learn a theory, build up knowledge, and apply this knowledge. I have nothing against the olympiad, however I have not got involved in it.

GMG: Do you think mathematicians need to be better at PR and salesmanship?

DL: Yes, I think this is important. I think that we generally are not very good at PR, we don't seem to be persuading any more students to do mathematics than we ever did. I'm not sure why that is, perhaps it is a hard subject and people go for easier options. Perhaps all the medical soaps depict being a doctor as glamorous, and this makes people do medicine, so perhaps we need a mathematical soap on television. We aren't good at PR and it's important that we get some good PR. Mathematicians tend to be modest and not good at selling the subject, so being a mathematician and being good at PR don't seem to go together. It's not in our nature to blow our own trumpets. We should have people doing it for us if we can't do it ourselves.

GMG: David, thank you very much. 
Gary McGuire,

School of Mathematical Sciences,

University College Dublin,

Dublin 4, Ireland

gary.mcguire@ucd.ie

Received on 2 September 2009. 